\title{
Suplementação de Novilhos Mestiços em Pastejo na Época de Transição Água-Seca: Desempenho Produtivo, Características Físicas de Carcaça, Consumo e Parâmetros Ruminais 1
}

\author{
Kelvin Shin-lti Kabeya ${ }^{2}$, Mário Fonseca Paulino ${ }^{3}$, Edenio Detmann ${ }^{4}$, Sebastião de Campos \\ Valadares Filho ${ }^{3}$, Paulo Roberto Cecon ${ }^{5}$, Domingos Sávio de Queiroz ${ }^{6}$, Paulo Gomes Júnior ${ }^{2}$, \\ Odilon Gomes Pereira ${ }^{3}$
}

\begin{abstract}
RESUMO - Dois experimentos foram conduzidos objetivando-se avaliar os efeitos da suplementação no período de transição águaseca (maio a setembro) sobre o desempenho produtivo, consumo de matéria seca (CMS), pH e N-amoniacal ruminais. Avaliaram-se suplementos com 30\% de proteína bruta, fornecidos em nível de $3 \mathrm{~kg} /$ animal/dia, constituídos pelas fontes energéticas milho-grão (MILHO), milho desintegrado com palha e sabugo (MDPS) e farelo de trigo (FT). No experimento 1, foram utilizados 15 novilhos mestiços holandês-zebu, com média de 18 meses e peso vivo de $350 \mathrm{~kg}$, em pastagem de Brachiaria brizantha cv. Marandu. Os animais exibiram ganhos médios de 0,$85 ; 0,88$; e $0,80 \mathrm{~kg} /$ animal/dia para os suplementos à base de MDPS, milho e farelo de trigo, respectivamente, não diferindo entre si. As características físicas de carcaça não foram afetadas por tratamentos. No experimento 2, empregaram-se cinco novilhos Limousin x Nelore, castrados, manejados em piquetes de Brachiaria decumbens. As mensurações apontaram reduções no CMS para os tratamentos FT e MDPS durante o mês de maio. Diferenças entre tratamentos quanto ao CMS foram observadas durante o mês de maio, sendo mais elevadas para MILHO, em comparação ao FT e MDPS. A concentração de amônia apresentou-se abaixo de 5 mg/dL de líquido de rúmen somente para o suplemento MILHO. O pH ruminal em todos os tratamentos manteve-se acima de 6,2.
\end{abstract}

Palavras-chave: capim-braquiária, consumo a pasto, suplementos múltiplos

\section{Supplementation of Crossbred Steers Under Grazing During the Rainy/Dry Transition Period: Performance, Carcass Physical Characteristics, Intake and Ruminal Parameters}

\begin{abstract}
Two experiments were carried out to evaluate the effects of the supplementation in the transition period between wet and dry seasons (May to September) on the productive performance, dry matter intake (DMI), and ruminal $\mathrm{pH}$ and N-ammonia. Supplements with $30 \%$ of crude protein, supplied in the level of $3 \mathrm{~kg} /$ animal/day and constituted by the following energy sources: corn grain (MILHO), grounded corn ear (MDPS) and wheat bran (FT), were evaluated. In the experiment 1, 15 holstein-zebu steers, with average age of 18 months and live weight of $350 \mathrm{~kg}$, were maintained in pasture of Brachiaria brizantha cv. Marandu. The animals showed average daily gain of .85, .88 , and $.80 \mathrm{~kg} / \mathrm{animal} /$ day for the supplements MDPS, MILHO and FT, respectively, and did not differ to each other. The carcass physical characteristics were not affected by the treatments. In the experiment 2, five limousin x nelore steers were maintained in pasture of Brachiaria decumbens. The measures pointed reductions in the DMI for the treatments FT and MDPS during May. Differences in DMI among treatments were observed during May, being higher for MILHO, compared to FT and MDPS. The ruminal ammonia concentration only became below $5 \mathrm{mg} / \mathrm{dL}$ for the MILHO supplement. The ruminal $\mathrm{pH}$ in all the treatments stayed above 6.2.
\end{abstract}

Key Words: multiple supplements, pasture intake, signal grass

\section{Introdução}

O consumo de matéria seca (MS) por animais em pastejo está relacionado diretamente com a disponibilidade e qualidade da forragem. Restrições na quantidade de forragem disponível levam à diminuição na ingestão de matéria seca, principalmente devido à redução do tamanho dos bocados, o que leva ao aumento no tempo de pastejo (Minson, 1990).

Pastagens tropicais e subtropicais são caracterizadas por rápida taxa de crescimento durante o período chuvoso, levando à maturidade das plantas, as quais contêm altos níveis de constituintes da parede celular. Os animais em pastejo têm disponibilidade de

\footnotetext{
${ }_{1}^{1}$ Parte da Dissertação de Mestrado em Zootecnia apresentada à UFV pelo primeiro autor.

${ }^{2}$ Mestre em Zootecnia pela UFV. E.mail: kelvinsk@terra.com.br

${ }^{3}$ Professor, Departamento de Zootecnia, Universidade Federal de Viçosa, Viçosa-MG, 36571-000. E.mail: mpaulino@mail.ufv.br

${ }^{4}$ Zootecnista, Doutor em Nutrição de Ruminantes, DZO-UFV. E.mail: detmann@alunos.ufv.br

${ }^{5}$ Professor, Departamento de Informática-UFV. E.mail: cecon@dpi.ufv.br

${ }^{6}$ Pesquisador da EPAMIG - Viçosa-MG.
} 
forragem de bom valor nutritivo por curto espaço de tempo, pois a pastagem, com a chegada da estação seca, decresce rapidamente em digestibilidade e, particularmente, em conteúdo total de nitrogênio $(\mathrm{N})$, o que leva à perda excessiva de peso, constituindo o principal fator limitante para a produção animal (Leng, 1984).

Segundo Minson (1990), o valor nutritivo das gramíneas tropicais é baixo no período da seca, pois a maioria não atinge o valor mínimo de 7,0\% de proteína bruta, o que limita o desenvolvimento dos microrganismos do rúmen, a digestibilidade e o consumo da forragem, resultando em baixo desempenho dos animais. Esta deficiência sazonal pode ser suprida pelo fornecimento de proteína adicional à dieta dos animais, tanto de origem vegetal, como também proveniente de compostos nitrogenados não-protéicos.

A uréia é incluída na alimentação de ruminantes, com o objetivo de substituir a proteína natural, de maior custo, ou acrescentar nitrogênio em sistemas de produção com forragens de baixo valor protéico. O principal objetivo da uréia na suplementação é manter a concentração de amônia ruminal em níveis elevados, aumentando, assim, o consumo por intermédio de melhorias na fermentação ruminal (Hunter \& Vercoe, 1984).

Segundo Playne \& Kennedy (1976), citados por Minson (1990), em animais alimentados com forragens tropicais maduras, a concentração de amônia ruminal apresenta correlação positiva com a concentração protéica. Para um crescimento microbiano adequado, a concentração amoniacal ruminal mínima deve situar-se próximo a $5,0 \mathrm{mg} / \mathrm{dL}$ de fluido ruminal (Satter \& Slyter, 1974). No entanto, divergentemente, Leng (1990) inferiu que, em condições tropicais, são necessárias concentrações superiores a $10 \mathrm{mg} / \mathrm{dL}$ para que haja maximização da digestão ruminal da matéria seca, e superiores a $20 \mathrm{mg} / \mathrm{dL}$, para que ocorra a maximização do consumo. Valores elevados dessa natureza permitem inferir que o nível crítico é diferente para o máximo consumo voluntário e crescimento microbiano.

Em regime de pastejo, a pastagem deve suprir a maior parte ou a totalidade dos nutrientes às exigências nutricionais dos animais. Um grande desafio é predizer com eficiência o impacto que a suplementação terá no desempenho animal. Uma estratégia de suplementação adequada seria aquela destinada a maximizar o consumo e a digestibilidade da forragem disponível.

Waldo (1986) relatou que a suplementação com concentrados em dietas baseadas em forragem amplia, na maioria das vezes, o consumo total de matéria seca, reduzindo, porém, a ingestão das forrageiras. Por outro lado, segundo o NRC (1984), as diferenças primárias nas respostas sobre o consumo parecem estar associadas com o teor protéico da forragem e quantidade de suplemento fornecido. Se a forragem apresenta baixo nível de proteína, o consumo será incrementado quando uma pequena quantidade de suplemento protéico for fornecido. Contudo, quando mais de $1 \mathrm{~kg}$ de suplemento é fornecido, o consumo de forragem poderá ser reduzido por substituição.

O objetivo do presente trabalho foi avaliar o efeito da suplementação sobre o desempenho produtivo, as características de carcaça, o consumo de matéria seca e os parâmetros ruminais em novilhos mestiços em pastejo, durante o período de transição água-seca.

\section{Material e Métodos}

O presente trabalho foi conduzido na Fazenda Experimental de Felixlândia, Minas Gerais (FEFX), da Empresa de Pesquisa Agropecuária de Minas Gerais (EPAMIG). A cidade de Felixlândia está situada a $18^{\circ} 04^{\prime} 04^{\prime \prime}$ latitude sul e $44^{\circ} 58^{\prime} 48^{\prime \prime}$ de longitude oeste, à altitude média de $616 \mathrm{~m}$. O clima da região é classificado como AW (tropical úmido de savana, com inverno seco e verão chuvoso), segundo classificação de Köepen. As condições climáticas obtidas durante o período experimental são mostradas na Tabela 1.

Foram conduzidos dois experimentos: no experimento 1, estudaram-se o desempenho produtivo e as características de carcaça de novilhos suplementados em pastagens de Brachiaria brizantha cv. Marandu; no experimento 2, avaliaram-se o consumo de matéria seca e os parâmetros ruminais em novilhos alimentados em pastagens de Brachiaria decumbens. Experimento 1 - Desempenho de bovinos suplementados

Uma área experimental com, aproximadamente, 12 hectares de pastagem de Brachiaria brizantha cv. Marandu foi dividida em três piquetes providos com bebedouro e comedouro coberto.

Foram utilizados 15 novilhos mestiços, com idade e peso médios inicias de 18 meses e $350 \mathrm{~kg}$. O período de avaliação constou de 116 dias, tendo início em 08 de maio e término em 02 de setembro de 1998.

Foram avaliados três suplementos denominados de tratamentos MDPS, constituído de milho desintegrado com palha e sabugo; MILHO, constituído de 
Tabela 1 - Temperaturas máximas e mínimas, umidade relativa do ar (URA) e precipitação total, no período de janeiro a agosto de 1998

Table 1 - Maximum and minimum temperatures, relative air moisture (RAM) and total rainfall, from January to August 1998

\begin{tabular}{|c|c|c|c|c|}
\hline \multirow[b]{2}{*}{$\begin{array}{l}\text { Mês } \\
\text { Month }\end{array}$} & \multicolumn{2}{|c|}{$\begin{array}{c}\text { Temperatura }\left({ }^{\circ} \mathrm{C}\right) \\
\text { Temperature }\end{array}$} & \multirow{2}{*}{$\begin{array}{c}\text { URA } \\
R A M \\
(\%)\end{array}$} & \multirow{2}{*}{$\begin{array}{l}\text { Precipitação } \\
\text { Rainfall } \\
\text { (mm) }\end{array}$} \\
\hline & $\begin{array}{l}\text { Máxima } \\
\text { Maximum }\end{array}$ & $\begin{array}{l}\text { Mínima } \\
\text { Minimum }\end{array}$ & & \\
\hline $\begin{array}{l}\text { Janeiro } \\
\text { January }\end{array}$ & 31,54 & 20,29 & 85,77 & 97,60 \\
\hline $\begin{array}{l}\text { Fevereiro } \\
\text { February }\end{array}$ & 32,26 & 20,62 & 73,68 & 241,00 \\
\hline $\begin{array}{l}\text { Março } \\
\text { March }\end{array}$ & 32,61 & 19,82 & 71,77 & 78,00 \\
\hline $\begin{array}{l}\text { Abril } \\
\text { April }\end{array}$ & 31,96 & 17,80 & 65,06 & 35,00 \\
\hline $\begin{array}{l}\text { Maio } \\
\text { May }\end{array}$ & 28,68 & 13,81 & 70,10 & 76,50 \\
\hline $\begin{array}{l}\text { Junho } \\
\text { June }\end{array}$ & 27,33 & 11,05 & 65,17 & 0 \\
\hline $\begin{array}{l}\text { Julho } \\
\text { July }\end{array}$ & 28,87 & 9,82 & 60,68 & 0 \\
\hline $\begin{array}{l}\text { Agosto } \\
\text { August }\end{array}$ & 31,10 & 14,32 & 54,65 & 18,30 \\
\hline $\begin{array}{l}\text { Média } \\
\text { Mean }\end{array}$ & 30,54 & 15,94 & 68,36 & 68,30 \\
\hline
\end{tabular}

Fonte: FEFX/Felixlândia.

Source:FEFX/Felixlândia.

fubá de milho; e FTRIGO, à base de farelo de trigo, formulado de acordo com os valores de composição relatados por Campos (1995), para conter 30\% de proteína bruta, com base na matéria seca, e fornecidos em quantidades pré-estabelecidas de $3,0 \mathrm{~kg} /$ cabeça/dia, equivalente a 2,57 kg MS, às $11 \mathrm{~h}$.

Nas Tabelas 2 e 3, são mostradas a composição percentual dos ingredientes e a composição químicobromatológica dos suplementos, respectivamente.

Todos os animais foram tratados contra ecto e endoparasitas, à base de ivermectina $1 \%$, no início do experimento. Os pesos inicial e final foram obtidos após jejum de alimento e água de 14 horas. As pesagens intermediárias dos animais foram executadas em intervalos de 28 dias, sem jejum prévio, procedendo-se, concomitantemente, ao rodízio dos animais entre piquetes. A cada rotação procedeu-se à amostragem da pastagem, para estimação da disponibilidade total de matéria seca, por intermédio do corte, ao nível do solo, de cinco áreas delimitadas por um quadrado metálico de $1 \times 1 \mathrm{~m}$ escolhidas aleatoriamente dentro de cada piquete, conforme descrito por McMeniman (1997).

Os animais foram abatidos por meio de concussão cerebral, com posterior secção da jugular, após jejum prévio de 16 horas. $\mathrm{O}$ abate ocorreu quando a média do peso vivo dos animais atingiu $441 \mathrm{~kg}$. Selecionaram-se, aleatoriamente, quatro animais de cada tratamento para avaliação das características físicas da carcaça.

Tabela 2 - Composição dos suplementos, com base na matéria natural

Table 2 - Composition of the supplements, as fed basis

\begin{tabular}{|c|c|c|c|}
\hline \multirow[t]{2}{*}{$\begin{array}{l}\text { Ingredientes (\%) } \\
\text { Ingredients }\end{array}$} & \multicolumn{3}{|c|}{$\begin{array}{l}\text { Tratamentos } \\
\text { Treatments }\end{array}$} \\
\hline & MDPS & Milho & Ftrigo \\
\hline $\begin{array}{l}\text { Sal mineral }{ }^{1} \\
\text { Salt }\end{array}$ & 2,00 & 2,00 & 2,00 \\
\hline $\begin{array}{l}\text { Uréia/sulfato de amônia 9:1 } \\
\text { Urea/ammonia sulfate 9:1 }\end{array}$ & 2,50 & 2,50 & 2,50 \\
\hline $\begin{array}{l}\text { Farelo de soja } \\
\text { Soybean meal }\end{array}$ & 45,00 & 40,00 & 30,00 \\
\hline $\begin{array}{l}\text { MDPS* } \\
\text { Grounded corn ear }\end{array}$ & 50,50 & - & - \\
\hline $\begin{array}{l}\text { Milho grão moído } \\
\text { Grounded corn }\end{array}$ & - & 55,50 & - \\
\hline $\begin{array}{l}\text { Farelo de trigo } \\
\text { Wheat bran }\end{array}$ & - & - & 65,50 \\
\hline
\end{tabular}

* Milho desintegrado com palha e sabugo (Grounded corn ear).

1 Composição percentual (Percent composition): fosfato bicálcico (dicalcium phosphate), 50,00; sal comum (salt), 48,00; sulfato de zinco (zinc sulfate), 1,50; sulfato de cobre (copper sulfate), 0,40 ; sulfato de cobalto (cobalt sulfate), 0,05 ; sulfato de magnésio (magnesium sulfate), 0,03; e iodato de potássio (potassium iodine), 0,03. 
Tabela 3 - Teores médios de matéria seca (MS), proteína bruta (PB), extrato etéreo (EE), digestibilidade in vitro da matéria seca (DIVMS), fibra detergente neutro indigestível (FDNi), fibra em detergente neutro isenta de cinza e proteína (FDNcp), nitrogênio insolúvel em detergente neutro (NIDN), cinzas, cálcio $(\mathrm{Ca})$ e fósforo $(\mathrm{P})$, expressos em porcentagem de matéria seca, para os diferentes suplementos

Table 3 - Average contents of dry matter (DM), crude protein $(C P)$, ether extract (EE), in vitro dry matter digestibility (IVDMD), indigestible neutral detergent fiber (NDFi), neutral detergent fiber without ashes and protein (NDFap), neutral detergent insoluble nitrogen (NDIN), ash, calcium (Ca, and phosphorus $(P)$, expressed in dry matter basis (\% of DM), according to the supplements

\begin{tabular}{|c|c|c|c|}
\hline \multirow[b]{2}{*}{ Item } & \multicolumn{3}{|c|}{$\begin{array}{l}\text { Suplementos } \\
\text { Supplements }\end{array}$} \\
\hline & MDPS & Milho & Ftrigo \\
\hline $\mathrm{MS}(D M)$ & 86,98 & 87,18 & 86,8 \\
\hline $\mathrm{PB}(C P)$ & 30,28 & 30,08 & 29,78 \\
\hline $\mathrm{EE}$ & 2,66 & 0,59 & 1,41 \\
\hline \multicolumn{4}{|l|}{ DIVMS } \\
\hline$I V D M D$ & 89,86 & 76,87 & 75,65 \\
\hline \multicolumn{4}{|l|}{ FDNi } \\
\hline$N D F i$ & 0,00 & 4,16 & 7,05 \\
\hline FDNcp (NDFap) & 4,61 & 24,80 & 21,16 \\
\hline $\mathrm{NIDN}^{1}(N D I N)$ & 19,46 & 16,58 & 13,30 \\
\hline Cinzas (Ash) & 5,82 & 8,12 & 6,07 \\
\hline $\mathrm{Ca}$ & 0,56 & 0,58 & 0,56 \\
\hline $\mathrm{P}$ & 0,53 & 1,02 & 0,50 \\
\hline
\end{tabular}

$1 \% \mathrm{~N}$-total $(\%$ total $N)$.

Após o abate, procedeu-se à mensuração e pesagem dos cortes. As carcaças foram divididas em duas metades, fazendo-se todas as mensurações na carcaça quente. $\mathrm{O}$ comprimento da meia-carcaça direita foi medido partindo-se da porção anterior medial da primeira costela até o ponto médio da curvatura do osso púbis.

Na meia-carcaça esquerda, na $12^{a}$ costela, foram determinadas a área de olho do músculo Longissimus dorsi (AOL) e a espessura de gordura subcutânea, que foi tomada sobre a secção do músculo Longissimus dorsi a $3 / 4$ do seu comprimento, a partir da coluna vertebral. Em seguida, procedeu-se à retirada da $9^{\mathrm{a}}, 10^{\mathrm{a}}$ e $11^{\mathrm{a}}$ costelas (Hankins \& Howe, 1946), denominada de seção H \& H. Imediatamente foi determinado o seu peso. As seções $\mathrm{H} \& \mathrm{H}$ foram devidamente identificadas e mantidas a $-10^{\circ} \mathrm{C}$, para posterior separação das frações de tecido ósseo, adiposo e muscular, cujas proporções foram empregadas, segundo equações descritas por Hankins \& Howe (1946), para estimação da composição física da carcaça total.
Estimou-se, na meia-carcaça direita, o rendimento dos cortes básicos: paleta, acém, ponta de agulha, alcatra completa e coxão. Para a separação do corte dianteiro e traseiro, seccionou-se entre a quinta e a sexta costelas, sendo o corte dianteiro dividido em acém e paleta completos e o corte traseiro, em ponta de agulha e traseiro especial (corte serrote), o qual foi dividido em coxão e alcatra completa.

Os dados foram interpretados estatisticamente por meio de análise de variância, segundo delineamento inteiramente casualizado. As comparações entre médias, de tratamentos foram realizadas por intermédio do teste de Student-Newman-Keulls (SNK), adotando-se o nível de $5 \%$ de probabilidade. Experimento 2 - Determinação do consumo voluntário e parâmetros ruminais

O experimento, delineado na época de transição água-seca, foi estabelecido em cinco piquetes de Brachiaria decumbens. Cada piquete apresentava área de 1,07 hectares, divisões com cerca eletrificada, providos de cocho coberto e bebedouro.

Para determinar o consumo voluntário de forragem e estimar o pH e a concentração de amônia ruminal, foram utilizados cinco bovinos F1 Limousin x Nelore, castrados com idade aproximada de 26 meses, peso médio inicial de $488 \mathrm{~kg}$, fistulados no esôfago e rúmen.

As avaliações foram realizadas ao início e final do período seco, centralizadas sobre os meses de maio e agosto. Cada época de avaliação foi composta por três períodos consecutivos, nos quais os animais receberam o mesmo suplemento, conforme descrição anterior (Tabelas 2 e 3). Cada período de avaliação constou de quinze dias, sendo os sete dias iniciais para a adaptação dos animais ao indicador externo, óxido crômico. $\mathrm{O}$ indicador foi fornecido em duas doses diárias de $10 \mathrm{~g}$ cada (8 e $17 \mathrm{~h}$ ). O suplemento era fornecido aos animais nos piquetes, na quantidade de $3 \mathrm{~kg} /$ cabeça/ dia, equivalente a $2,57 \mathrm{~kg}$ de matéria seca, uma única vez ao dia, durante o período de avaliação, logo após a primeira aplicação do indicador.

Do oitavo ao décimo terceiro dia, realizou-se a coleta de fezes via reto, concomitante à de aplicação do indicador, em quantidade aproximada de $300 \mathrm{~g}$. Imediatamente após a coleta, as amostras foram acondicionadas em sacolas plásticas identificadas e congeladas a $-10^{\circ} \mathrm{C}$. Coletaram-se fezes durante cinco dias, do oitavo ao décimo segundo dia.

Ao início de cada período procedeu-se à amostragem da pastagem por intermédio de simula- 
ção manual de pastejo, objetivando-se avaliar a forragem ingerida pelos animais. A composição média das amostras é expressa na Tabela 4.

Posteriormente, as amostras de fezes foram compostas com base no peso seco ao ar, por tratamento e período, e analisadas quanto ao teor de cromo, em espectrofotômetro de absorção atômica, conforme metodologia descrita por Willians et al. (1962). Para determinação da produção fecal, utilizou-se a fórmula:

$$
\mathrm{PF}=\mathrm{OF} / \mathrm{COF}
$$

em que $\mathrm{PF}$ refere-se à produção fecal diária (g/dia); $\mathrm{OF}$, ao óxido crômico fornecido (g/dia); e COF, à concentração óxido crômico nas fezes (g/gMS).

Para a determinação do consumo de matéria seca, utilizou-se o indicador interno fibra em detergente neutro indigestível (FDNi), conforme marcha adaptada de Cochran et al. (1986), incubando-se $650 \mathrm{mg}$ de amostra (ingredientes, pastejo simulado e fezes) por 144 horas, a $39 \pm 0,3^{\circ} \mathrm{C}$, em tubos equipados com válvula de bunsen, com 25,0 mL de saliva artificial de McDougal (McDougal, 1949) e 25,0 mL de líquido

Tabela 4 - Teores médios de matéria seca (MS), proteína bruta (PB), extrato etéreo (EE), digestibilidade in vitro da matéria seca (DIVMS), fibra detergente neutro indigestível (FDNi), fibra em detergente neutro (FDN), cinzas, cálcio $(\mathrm{Ca})$ e fósforo $(\mathrm{P})$, expressos em porcentagem de matéria seca, para as amostras de pastejo simulado, em função da época de amostragem

Table 4 - Average contents of dry matter (DM), crude protein (CP), ether extract (EE), in vitro dry matter digestibility (IVDMD), indigestible neutral detergent fiber (NDFi), neutral detergent fiber (NDF), ash, calcium (Ca), and phosphorus $(P)$, expressed in dry matter base, for handplucking samples according to month of sampling

\begin{tabular}{lcc}
\hline & \multicolumn{2}{c}{$\begin{array}{c}\text { Mês } \\
\text { Month }\end{array}$} \\
\cline { 2 - 3 } Item & Maio & Agosto \\
& May & 46,03 \\
MS $(D M)$ & 35,93 & 4,46 \\
PB $(C P)$ & 3,95 & 0,87 \\
EE & 0,75 & \\
DIVMS & & 56,98 \\
IVDMD & 51,33 & \\
FDNi & & 26,49 \\
NDFi & 32,55 & 71,96 \\
FDN $(N D F)$ & 71,83 & 6,96 \\
Cinzas $($ Ash $)$ & 6,72 & 0,39 \\
Ca & 0,33 & 0,18 \\
P & 0,19 &
\end{tabular}

ruminal. Posteriormente, submeteu-se ao tratamento térmico com solução de detergente neutro, durante uma hora. Para filtragem, foi utilizado cadinho de porosidade número zero, previamente seco e tarado.

As estimativas de consumo foram obtidas pela seguinte equação:

$$
\mathrm{CMS}=\{[(\mathrm{PF} * \mathrm{CIFZ})-\mathrm{IS}] / \mathrm{CIFR}\}+\mathrm{CMSS}
$$

em que: $\mathrm{CMS}=$ consumo de matéria seca $(\mathrm{kg} / \mathrm{dia})$; $\mathrm{PF}=$ produção fecal $(\mathrm{kg} / \mathrm{dia}) ; \mathrm{CIFZ}=$ concentração do indicador presente nas fezes $(\mathrm{kg} / \mathrm{kg}) ; \mathrm{IS}=$ indicador presente no suplemento $(\mathrm{kg} / \mathrm{dia}) ; \mathrm{CIFR}=$ concentração do indicador presente na forragem $(\mathrm{kg} / \mathrm{kg})$; e $\mathrm{CMSS}=$ consumo de matéria seca do suplemento $(\mathrm{kg} / \mathrm{dia})$.

Dois dias após a última aplicação do indicador óxido crômico, ou seja, no décimo quinto dia, procedeu-se à coleta de líquido ruminal para a determinação do pH e amônia ruminal.

A coleta de líquido ruminal foi realizada às $0,2,4$ e 6 horas após o fornecimento do suplemento, com filtragem em camada tripla de gazes, sendo o suplemento fornecido aos animais a partir das oito horas. $\mathrm{O}$ pH foi determinado em peagâmetro digital. Coletaram-se, aproximadamente, $100 \mathrm{~mL}$ de líquido ruminal na região intermediária do rúmen, entre as fases sólida e líquida, para a leitura de $\mathrm{pH}$, e posteriormente acondicionaram-se $40 \mathrm{~mL}$ em frasco contendo 1,0 $\mathrm{mL}$ de $\mathrm{HCl} 1: 1$, que foi imediatamente armazenado a $-10^{\circ} \mathrm{C}$, para posterior análise de amônia.

O líquido ruminal foi descongelado e imediatamente centrifugado a $3.000 \mathrm{rpm}$, durante 10 minutos, sendo recolhido o sobrenadante. Para a análise de teor de nitrogênio amoniacal total, foi utilizada a marcha adaptada de Fenner, citada por Vieira (1980). Foi utilizada uma alíquota de 2,0 mL do sobrenadante e 10,0 mL de KOH (2 N) para a destilação. Recolheuse o destilado $(100,0 \mathrm{~mL})$ em erlenmeyer contendo $10,0 \mathrm{~mL}$ de ácido bórico. Para a titulação empregouse ácido clorídrico $(0,005 \mathrm{~N})$.

Para os valores obtidos de $\mathrm{pH}$ e amônia, os modelos foram escolhidos com base na significância dos coeficientes de regressão, utilizando-se o teste de $\mathrm{F}$, e no coeficiente de determinação.

O experimento foi analisado em delineamento inteiramente casualizado, seguindo esquema fatorial $3 \times 2$, segundo o modelo:

$$
Y i j k=\mu+S_{i}+E_{j}+S_{i j}+e_{i j k}
$$

em que: $S_{i}=$ efeito do suplemento i, sendo $i=1,2$ e 3 ; $E_{j}=$ efeito da época de avaliação $j$, sendo $j=1$ e 2 ; e $\mathrm{SE}_{\mathrm{ij}}=$ interação entre os fatores principais. 


\section{Resultados e Discussão}

\section{Desempenho dos animais}

$\mathrm{Na}$ Tabela 5 são expressas a disponibilidade e oferta médias de forragem durante o período experimental. Os altos valores obtidos permitem inferir sobre a inexistência de entraves sobre a seletividade, garantindo-se, neste aspecto, a possibilidade de maximização do consumo de matéria seca de forragem.

$\mathrm{Na}$ Tabela 6, são apresentadas as médias de ganho de peso vivo diário, nos tratamentos avaliados. Não houve diferença $(\mathrm{P}>0,05)$ no ganho de peso animal entre os tratamentos testados, embora o suplemento à base de MILHO tenha ensejado diferencial próximo de $10 \%$ sobre o suplemento à base de farelo de trigo. Esta diferença pode estar relacionada ao maior consumo de matéria seca para o MILHO (Tabela 9). Também pode ter ocorrido potencialização dos microrganismos digestores da fibra, proporcionado pelas características bromatológicas do suplemento, devido à alta constituição de carboidratos não-fibrosos (CNF) e ausência de porção não-degradável da parede celular (FDNi) em MILHO (Tabela 3).

Na Tabela 7, apresentam-se as médias e os respectivos coeficientes de variação para as porcentagens e quantidades de músculo(MUS), gordura (GOR) e ossos (OSS), o comprimento de carcaça (CCAR), a gordura subcutânea (GOSUB), o rendimento de carcaça em relação ao peso vivo (RCPV), a área de olho de lombo (AOL), a relação músculo:osso (RELMO) e a relação gordura:músculo (RELGM), em função dos tratamentos MDPS, MILHO e FTRIGO. Não foi encontrada diferença significativa $(\mathrm{P}>0,05)$ entre os suplementos avaliados para as características da carcaça.

Segundo Müller (1980), no momento do abate, a gordura subcutânea deve apresentar o mínimo de 3 a $5 \mathrm{~mm}$ de espessura para melhor conservação e

Tabela 5 - Disponibilidade (kg MS/ha) e oferta (kg MS/ animal/dia) médias de forragem durante 0 período experimental, em função dos diferentes tratamentos

Table 5 - Mean availability ( $k g$ DM/ha) and offer ( $k g$ DM/animal/ day) of forage during the experimental period, according to the treatments

\begin{tabular}{lcc}
\hline $\begin{array}{l}\text { Tratamento } \\
\text { Treatment }\end{array}$ & $\begin{array}{c}\text { Disponibilidade } \\
\text { Availability }\end{array}$ & $\begin{array}{c}\text { Oferta } \\
\text { Offer }\end{array}$ \\
\hline MDPS & $10.503,8$ & 72,94 \\
Milho & $9.799,1$ & 67,58 \\
Ftrigo & $9.836,8$ & 67,84 \\
\hline
\end{tabular}

minimização de danos à carcaça por resfriamento.Os animais de todos os tratamentos avaliados apresentaram GOSUB $(4,77$ a 5,19 mm) compatível com os requisitos exigidos, mostrando a viabilidade de produção de carne de qualidade via suplementação de bovinos em pastejo durante a época seca. Zervoudakis (2000), em trabalho de desempenho animal a pasto no período chuvoso, encontrou para a mesma variável valor médio de 7,45 $\mathrm{mm}$.

O comprimento de carcaça não foi influenciado pelo suplemento fornecido, resultado este justificável, uma vez que tratam-se de animais com padrão genético semelhante e submetidos a nível moderado de energia. Os valores encontrados para a variável CCAR são inferiores aos obtidos por Zervoudakis (2000) e Jorge (1997), entretanto apresentaram-se superiores aos obtidos por Gesualdi Jr. (1999), Oliveira et al. (1998) e Ferreira et al. (1997), em condições de confinamento.

$\mathrm{O}$ rendimento de carcaça em relação ao peso vivo, semelhantemente às demais variáveis avaliadas, não foi afetado por tratamentos. O RCPV é altamente influenciado pelo peso vivo do animal; assim, sendo os animais dos diferentes tratamentos abatidos com pesos semelhantes, uma vez não havendo efeitos significativos sobre GMD ( $>>0,05)$, este resultado é plenamente justificável. Em adição, Berg $\&$ Butterfield (1976) afirmaram que o rendimento de carcaça é diretamente proporcional ao nível de tecido adiposo presente na carcaça. Tecendo raciocínio semelhante, a não observação de efeitos significativos sobre GOR $(\mathrm{P}>0,05)$ amplia o suporte sobre a ausência de efeitos sobre RCPV.

Moletta\&Perotto(1997)encontraram valorde 54,81\% de RCPV para animais terminados a pasto com idade de 29 meses, o qual é próximo ao do presente trabalho.

$\mathrm{O}$ suplemento à base de milho, embora sem significância $(\mathrm{P}>0,05)$, apresentou-se numericamente

Tabela 6 - Médias de ganho de peso diário (GPD) e coeficiente de variação (CV), em função dos tratamentos

Table 6 - Means of daily weight gain (DWG) and coefficient of variation $(\mathrm{CV})$, according to the treatments

\begin{tabular}{lcccr}
\hline & \multicolumn{4}{c}{$\begin{array}{c}\text { Tratamentos } \\
\text { Treatments }\end{array}$} \\
\cline { 2 - 5 } & MDPS & Milho & Ftrigo & CV $(\%)$ \\
\hline GPD $(\mathrm{kg} / \text { dia })^{1}$ & 0,85 & 0,88 & 0,80 & 20,44
\end{tabular}

$D W G$

${ }^{1}$ Médias na linha não diferem $(P<0,05)$ pelo teste SNK.

${ }^{1}$ Means, within a row, do not differ $(P<.05)$ by SNK test. 
Tabela 7 - Médias e coeficientes de variação para as porcentagens e quantidades de músculo (MUS), gordura (GOR) e ossos (OSS), o comprimento de carcaça (CCAR), a gordura subcutânea (GOSUB), o rendimento de carcaça (RCPV), a área de olho de lombo (AOL), a relação músculo:osso (RELMO) e a relação gordura:músculo (RELGM), em função dos tratamentos

Table 7 - Means and coefficients of variation (CV) for the percentages and amounts of muscle (MUS), fat (GOR) and bone (OSS), carcass length (CCAR), subcutaneous fat (GODSUB), carcass dressing (RCPV), loin eye area (AOL), muscle:bone ratio (RELMO) and fat:muscle ratio (RELGM), according to the treatments

\begin{tabular}{|c|c|c|c|c|c|}
\hline \multirow[b]{2}{*}{$\begin{array}{l}\text { Variáveis } \\
\text { Variables }\end{array}$} & \multicolumn{3}{|c|}{$\begin{array}{c}\text { Tratamentos } \\
\text { Treatments }\end{array}$} & \multirow[b]{2}{*}{$\begin{array}{l}\text { Médias } \\
\text { Means }\end{array}$} & \multirow[b]{2}{*}{$\mathrm{CV}(\%)$} \\
\hline & MDPS & Milho & Ftrigo & & \\
\hline MUS(\%) & 55,15 & 57,17 & 58,31 & 56,87 & 8,80 \\
\hline GOR(\%) & 28,37 & 27,67 & 22,85 & 26,29 & 19,60 \\
\hline OSS (\%) & 16,98 & 16,05 & 18,67 & 17,23 & 13,22 \\
\hline MUS (kg) & 124,64 & 134,38 & 132,68 & 130,57 & 12,35 \\
\hline GOR (kg) & 65,11 & 65,59 & 52,71 & 61,13 & 28,54 \\
\hline OSS $(\mathrm{kg})$ & 38,41 & 37,55 & 42,21 & 39,39 & 11,95 \\
\hline CCAR $(\mathrm{cm})$ & 135,00 & 132,25 & 132,25 & 133,16 & 3,60 \\
\hline $\operatorname{GOSUB}(\mathrm{mm})$ & 4,83 & 4,77 & 5,19 & 4,93 & 31,38 \\
\hline RCPV (\%) & 53,39 & 54,31 & 54,70 & 54,13 & 6,77 \\
\hline $\mathrm{AOL}\left(\mathrm{cm}^{2}\right)$ & 85,69 & 96,81 & 87,93 & 90,14 & 19,78 \\
\hline RELMO & 3,27 & 3,59 & 3,20 & 3,35 & 16,44 \\
\hline RELGM & 0,53 & 0,48 & 0,39 & 0,47 & 28,37 \\
\hline
\end{tabular}

Médias na linha não diferem $(\mathrm{P}>0,05)$ pelo teste SNK (Means, within a row, do not differ [P>.05] by SNK test).

superior para as variáveis área de olho de lombo (AOL) e proporção de músculo (MUS), sendo também observadas maior relação numérica músculo-osso (RELMO) e concentração de gordura (GOR) na carcaça.

O percentual médio de ossos obtidos foi de $17,23 \%$, não sendo observadas diferenças significativas entre os tratamentos avaliados $(\mathrm{P}>0,05)$. Sendo o tecido ósseo de maturidade precoce, é justificável pequena variação entre animais em terminação recebendo suplementos com nível moderado de energia. Müller \& Primo (1986) encontraram valores próximos a $16 \%$ para animais da raça Hereford abatidos aos dois anos de idade, com pastagem de inverno na desmama e sobreano. Moletta \& Perotto (1997) também encontraram valores próximos a $16 \%$ para animais terminados a pasto.

$\mathrm{Na}$ Tabela 8, apresentam-se as médias e seus respectivos coeficientes de variação, expressos em porcentagem dos cortes dianteiro (RD), traseiro (RT), traseiro especial (RTE), paleta (RPAL), acém-completo (RACEM), ponta de agulha (RPAGU), alcatra completa (RALC) e coxão (RCOX), em função dos tratamentos MDPS, MILHO e FTRIGO. Não houve efeito $(\mathrm{P}>0,05)$ dos diferentes suplementos sobre os rendimentos dos cortes e as proporções de traseiro especial. Estes resultados agregam à afirmação de Berg \& Butterfield (1976), de que, em condições normais, os animais apresentam tendência de equilíbrio entre quartos dianteiro e traseiro; portanto, os que possuem maior peso na parte posterior do corpo tendem a mostrar, igualmente, maior peso da parte anterior.

Os valores obtidos neste ensaio para RT e RTE foram superiores aos encontrados por Muniz et al. (1997) e Gesualdi Jr. (1999). Apenas o tratamento MDPS, embora não diferindo dos demais $(\mathrm{P}>0,05)$, apresentou valor superior para RTE $(48,84)$, comparativamente aos resultados obtidos por Zervoudakis (2000).

Consumo de matéria seca, $\mathrm{pH}$ e amônia ruminais

Apresentam-se na Tabela 9 as médias de consumo de matéria seca, expressas em \%PV. Foram observados efeitos significativos para os efeitos época, suplementos e sua interação $(\mathrm{P}<0,05)$.

No mês de agosto, não foram encontradas diferenças $(\mathrm{P}>0,05)$ entre os tratamentos avaliados, expressos em \%PV. Entretanto, no mês de maio, o consumo de matéria seca foi maior $(\mathrm{P}<0,05)$ com a utilização do suplemento à base de MILHO. Paralelamente, observou-se menor consumo durante o mês de maio para os suplementos MDPS e FTRIGO, quando comparados ao mês de agosto $(\mathrm{P}<0,05)$.

A medida de repleção ruminal dos constituintes fibrosos de um alimento permite, de forma conjunta, avaliar os efeitos de interação das cinéticas de trânsito e digestão sobre a capacidade de enchimento no compartimento ruminal. Vieira et al. (1997), ao avaliarem o efeito de repleção ruminal em capimelefante (Pennisetum purpureum Schum.), observaram elevação de 19,5 para 43,2 horas para idades de corte de 61 e 124 dias, destacando que a porção 
Tabela 8 - Médias e coeficientes de variação (CV) para os rendimentos dos cortes dianteiro (RD), traseiro (RT) e traseiro especial (RTE), paleta (RPAL), acém-completo (RACEM), ponta de agulha (RPAGU), alcatra completa (RALC) e coxão (RCOX), em função dos tratamentos

Table 8 - Means and coefficients of variation (CV) for the hindquarter (RD), forequarter (RT) and pistola style cut yields (RTE), shoulder yield (RPAL), whole acem yield (RACEM), spare ribs yield (RPAGU), whole rump (RALC) and round yield (RCOX), according to the treatments

\begin{tabular}{|c|c|c|c|c|c|}
\hline \multirow[b]{2}{*}{$\begin{array}{l}\text { Variáveis } \\
\text { Variables }\end{array}$} & \multicolumn{3}{|c|}{$\begin{array}{c}\text { Tratamentos } \\
\text { Treatments }\end{array}$} & \multirow[b]{2}{*}{$\begin{array}{l}\text { Médias } \\
\text { Means }\end{array}$} & \multirow[b]{2}{*}{$\mathrm{CV}(\%$} \\
\hline & MDPS & Milho & Ftrigo & & \\
\hline$\overline{\mathrm{RD}}$ & 38,79 & 39,43 & 39,30 & 39,17 & 1,97 \\
\hline RT & 61,21 & 60,56 & 60,69 & 60,82 & 1,27 \\
\hline RTE & 48,84 & 47,20 & 47,48 & 47,84 & 2,53 \\
\hline RPAL & 18,21 & 18,75 & 19,63 & 18,86 & 15,69 \\
\hline RACEM & 20,57 & 20,68 & 19,67 & 20,31 & 14,80 \\
\hline RPAGU & 12,36 & 13,36 & 13,21 & 12,98 & 8,25 \\
\hline RALC & 19,76 & 19,58 & 19,24 & 19,53 & 5,44 \\
\hline RCOX & 29,07 & 27,62 & 28,24 & 28,31 & 3,82 \\
\hline
\end{tabular}

Médias na linha não diferem $(\mathrm{P}>0,05)$ pelo teste SNK (Means, within a row, do not differ [P>.05] by SNK test).

indigestível da fibra respondera por 32 e $77 \%$ do efeito total, respectivamente. Embora existam evidências de adaptação do animal ao aumento no conteúdo de componentes indigestíveis na dieta por intermédio da ampliação do volume e pool de digesta residente no rúmen (Schettini et al., 1999), limites são definidos, além dos quais o consumo é reduzido permanentemente (Van Soest, 1994).

Dessa forma, a maior concentração de FDNi observada durante o mês de maio (Tabela 4) pode ter efetivamente colaborado para o menor consumo de MS observado sobre os suplementos MDPS e FTRIGO, por ocasionar maior efeito de repleção ruminal. Possivelmente, o menor consumo observado para MDPS, em relação a MILHO, na avaliação realizada em maio pode se embasar parcialmente sobre este princípio, dado seu elevado teor de FDNi frente aos demais tratamentos (Tabela 3 ).

$\mathrm{Na}$ Tabela 10, apresentam-se as equações de regressão ajustadas e os respectivos coeficientes de determinação para $\mathrm{pH}$ e amônia ruminal, com base nos tratamentos e na época avaliada.

Apenas o suplemento à base de farelo de trigo (FTRIGO) afetou o $\mathrm{pH}$ ruminal, de forma linear e quadrática, em função dos tempos de coleta, respectivamente, para os meses de maio e agosto. Para o mês de maio, o tratamento FTRIGO apresentou redução de 0,046 porunidade hora, enquanto no mês de agosto atingiu o valor máximo $(6,7)$ às 2,40 horas após o fornecimento do suplemento. $\mathrm{O} \mathrm{pH}$ para os demais tratamentos não foi influenciado $(\mathrm{P}>0,05)$ pelo tempo de coleta.

Os valores de $\mathrm{pH}$ sempre mantiveram-se acima de 6,2, limite considerado por Mould et al. (1983) e Hoover (1986) como inibitório ao desenvolvimento dos microrganismos celulolíticos.

Detmann et al. (1999), em condições de trabalho semelhantes, avaliando diferentes tipos de suplementos, encontrou valores de $\mathrm{pH}$ sempre acima de 6,3. Zervoudakis (2000) também não verificou diferenças significativas para a variável $\mathrm{pH}$ ruminal entre os tempos de coleta de $0,2,4$ e 6 horas, sendo o menor valor encontrado de 6,2. Franco et al. (1998), analisando diferentes níveis de degradabilidade de proteína em pastagem de $B$. brizantha, encontraram $\mathrm{pH}$ médio de 6,6 .

Tabela 9 - Consumos médios de matéria seca, expressos em \%PV, e coeficiente de variação, em função da interação entre mês e tratamentos

Table 9 - Average intakes of dry matter, express in \% of live weight, and coefficient of variation, according to month and treatment interaction

\begin{tabular}{|c|c|c|c|}
\hline \multirow[b]{2}{*}{$\begin{array}{l}\text { Mês } \\
\text { Month }\end{array}$} & \multicolumn{3}{|c|}{$\begin{array}{c}\text { Tratamentos }^{1} \\
\text { Treatments }\end{array}$} \\
\hline & MDPS & Milho & Ftrigo \\
\hline $\begin{array}{l}\text { Maio } \\
\text { May }\end{array}$ & $2,02^{\mathrm{Bc}}$ & $2,31^{\mathrm{Aa}}$ & $2,18^{\mathrm{Bb}}$ \\
\hline $\begin{array}{l}\text { Agosto } \\
\text { August }\end{array}$ & $2,34^{\mathrm{Aa}}$ & $2,29^{\mathrm{Aa}}$ & $2,32^{\mathrm{Aa}}$ \\
\hline CV $(\%)$ & & 2,09 & \\
\hline
\end{tabular}

${ }^{1}$ Médias, na coluna, seguidas por letras maiúsculas diferentes, ou na linha, seguidas por letras minúsculas diferentes, são diferentes $(\mathrm{P}<0,05)$ pelo teste SNK.

1 Means, within a column, followed by different capital letters, or within a row, followed by different small letters, are different $(P<.05)$ by Newman Keulls test. 
Tabela 10 - Equações de regressão ajustadas e coeficientes de determinação para pH e amônia (mg/dL), em função do tempo de coleta $(\mathrm{H})$ para cada tratamento e da época de avaliação

Table 10 - Fitted regression equations and the respective coefficients of determination for $\mathrm{pH}$ and ammonia (mg/dL), in function of the collection time $(h)$, according to the treatments and periods of evaluation

\begin{tabular}{lcllc}
\hline Item & $\begin{array}{c}\text { Tratamentos } \\
\text { Treatments }\end{array}$ & $\begin{array}{c}\text { Época } \\
\text { Period }\end{array}$ & $\begin{array}{c}\text { Equações ajustadas } \\
\text { Fitted equations }\end{array}$ & $\mathrm{r}^{2} / \mathrm{R}^{2}$ \\
\hline MH & MDPS & Maio & $\hat{\mathrm{Y}}=6,6$ & - \\
$\mathrm{pH}$ & Milho & & $\hat{\mathrm{Y}}=6,3$ & - \\
& Ftrigo & & $\hat{\mathrm{Y}}=6,3-0,0460 * \mathrm{H}$ & - \\
Amônia & MDPS & & $\hat{\mathrm{Y}}=29,7$ & - \\
Ammonia & Milho & & $\hat{\mathrm{Y}}=5,6$ & - \\
& Ftrigo & & $\hat{\mathrm{Y}}=26,1$ & - \\
& MDPS & Agosto & $\hat{\mathrm{Y}}=6,9$ & - \\
$\mathrm{pH}$ & Mugust & $\hat{\mathrm{Y}}=6,5$ & 0,99 \\
& Milho & & $\hat{\mathrm{Y}}=6,6+0,1167 * \mathrm{H}-0,0243 * \mathrm{H}^{2}$ & - \\
Amônia & Ftrigo & & $\hat{\mathrm{Y}}=29,9$ & - \\
Ammonia & MDPS & & $\hat{\mathrm{Y}}=4,1$ & - \\
& Milho & & $\hat{\mathrm{Y}}=20,9$ & \\
\hline
\end{tabular}

${ }^{*} \mathrm{~F}$ significativo a $5 \%$ (Significant at $5 \%$ ).

O suplemento à base de fubá de milho apresentou concentração de amônia ruminal de 5,6 e 4,1 ml/dL, para os meses de maio e agosto, respectivamente. Para o mês de agosto, o tratamento MILHO apresentou concentração de amônia ruminal inferior ao valor limite, 5,0 mg/dL de fluido ruminal, preconizado por Satter \& Slyter (1974). No mês de maio, o valor de amônia ruminal para o MILHO, embora esteja acima do valor limite proposto por Satter \& Slyter(1974), está aquém do mínimo de $10 \mathrm{mg} / \mathrm{dL}$ de líquido ruminal considerado como ótimo para adequada fermentação, sugerido por Leng (1990), em condições tropicais.

Os suplementos à base de MDPS e FTRIGO apresentaram concentrações de amônia ruminal superiores ao valor considerado crítico nos meses avaliados de maio e agosto. Os valores observados de amônia ruminal, exceto para o FTRIGO no mês de agosto, estão acima do nível recomendado por Mehrez \& Orskov (1977), de 23,0 mg N-NH $3 / \mathrm{dL}$ de fluido ruminal, tido como ideal para a obtenção de taxa máxima de fermentação. Também estão acima da sugestão de LENG (1990), que, em condições tropicais, sugere o nível de amônia acima de $20 \mathrm{mg} / \mathrm{dL}$ para a maximização do consumo de MS.

Em enfoque comparativo, a maior concentração amoniacal observada em MDPS e FTRIGO, frente ao tratamento MILHO, pode consistir reflexo de menor sincronização energia x proteína degradável atribuída à alta degradabilidade protéica do farelo de trigo (Valadares Filho et al., 1990) e menor digestibilidade do MDPS (Tabela 3). Em paralelo, este quadro exerceu, possivelmente, influência sobre o crescimento microbiano, o que poderia acarretar efeitos negativos sobre a degradação ruminal dos componentes fibrosos da forragem, ampliando-se o efeito de repleção da porção digestível da FDN, o que pode acrescer sobre a justificativa para o menor consumo observado para MDPS e FTRIGO durante o mês de maio.

\section{Conclusões}

Os suplementos testados foram equivalentes em termos de desempenho e características de carcaça dos animais.

As variações no consumo de matéria seca entre períodos de avaliação envolveram interações com o nível de fibra indigestível da forragem.

As diferenças de consumo entre suplementos podem ser atribuídas, possivelmente, a diferenças na sincronização energia x proteína no ambiente ruminal.

\section{Agradecimento}

À Empresa de Pesquisa Agropecuária de Minas Gerais (EPAMIG), pelo apoio durante a execução deste trabalho. 


\section{Literatura Citada}

BERG, R.T.; BUTTERFIELD, R.M. Nuevos conceptos sobre desarrollo de ganado vacuno. Zaragoza: Acribia, 1976. 207p.

CAMPOS, J. Tabelas para cálculo de rações. 2.ed. Viçosa: Universidade Federal de Viçosa, 1995. 64p.

COCHRAN, R.C.; ADAMS, D.C.; WALLACE, J.D. et al. Predicting digestibility of different diets with internal markers: evaluation of four potential markers. Journal of Animal Science, v.63, p.1476, 1986.

DETMANN, E.; PAULINO, M.F.; ZERVOUDAKIS, J.T. et al. Suplementação de novilhos mestiços no período das águas. 2. pH e amônia ruminal. In: REUNIÃO ANUAL DA SOCIEDADE BRASILEIRA DE ZOOTECNIA, 36., 1999, Porto Alegre. Anais... Porto Alegre: Sociedade Brasileira de Zootecnia, 1999. p.244.

FERREIRA, M.A.; VALADARES FILHO, S.C.; COELHO DA SILVA, J.F. et al. Consumo, conversão ganho de peso e características da carcaça de bovinos F1 Simental-Nelore, alimentados com diferentes níveis de concentrado das rações. In: REUNIÃO ANUAL DA SOCIEDADDE BRASILEIRA DE ZOOTECNIA, 34., 1997, Juiz de Fora. Anais... Juiz de Fora: Sociedade Brasileira de Zootecnia, 1997. p.280.

FRANCO, G.L.; ANDRADE, P.; BRUNO FILHO, J.R.B. Efeito de diferentes degradabilidades da proteína e suas quantidades sobre os parâmetros $\mathrm{pH}$ e N-NH${ }_{3}$ ruminal. In: REUNIÃO ANUAL DA SOCIEDADE BRASILEIRA DE ZOOTECNIA, 35., 1998, Botucatu. Anais... Botucatu: Sociedade Brasileira de Zootecnia, 1998. p.386-388.

GESUALDI Jr., A. Níveis de concentrado na dieta de novilhos F1 Limousin $x$ Nelore, em confinamento: desempenho produtivo e características de carcaça. Viçosa, MG: Universidade Federal de Viçosa, 1999. 62p. Dissertação (Mestrado em Zootecnia) - Universidade Federal de Viçosa, 1999.

HANKINS, O.G.; HOWE, P.E. Estimation of the composition of beef carcasses and cuts. Washington: USDA, 1946. (Technical Bulletin - USDA, 926).

HOOVER, W.H. Chemical factors involved in ruminal fiber digestion. Journal of Dairy of Science, v.68, n.1, p.40-44, 1986.

HUNTER, R.A.; VERCOE, J.E. The role of urea in the nutrition of ruminants fed low quality roughage diets. Outlook in Agriculture, v.13, n.3, p.154-159, 1984.

JORGE, A.M. Desempenho produtivo, características e composição corporal e da carcaça de zebuínos de quatro raças, abatidos em diferentes estágios de maturidade. Viçosa, MG: Universidade Federal de Viçosa, 1997. 99p. Tese (Doutorado em Zootecnia) - Universidade Federal de Viçosa, 1997.

LENG, R.A. Supplementation of tropical and subtropical pastures for ruminant production. In: GILCHRIST, F.M.C.; MACKIE, R.I. (Eds.) Herbivore nutrition in the subtropics and tropics. Craighall, South Africa: The Science Press, 1984. p.129-144.

LENG, R.A. Factors affecting the utilization of "poor - quality" forages by ruminants particularly under tropical conditions. Nutrition Research and Review, v.3, n.3, p.277-303, 1990.

McDOUGAL, E.I. Studies on ruminal saliva. 1. The composition and output of sheeps saliva. Biochemistry Journal, v.43, n.1, p.99-109, 1949.

McMENIMAN, N.P. Methods of estimating intake of grazing animals. In: SIMPÓSIO SOBRE TÓPICOS ESPECIAIS EM ZOOTECNIA. REUNIÃO ANUAL DA SOCIEDADE BRASILEIRA DE ZOOTECNIA, 34., 1997, Juiz de Fora. Anais... Juiz de Fora: Sociedade Brasileira Zootecnia, 1997. p.131-168.

MEHREZ, A.Z.; ORSKOV, E.R. A study of the artificial fiber bag technique for determining the digestibility of feeds in the rumen. Journal of Agricultural Science, v.88, n.3, p.645-650, 1977.

MINSON, D.J. Forage in ruminant nutrition. New York: Academic Press, 1990. 483p.

MOLETTA, J.L.; PEROTTO, D. Efeito do manejo alimentar no pré e/ou pós-desmame, sobre o desempenho e características de carcaça de novilhos. In: REUNIÃO ANUAL DA SOCIEDADDE BRASILEIRA DE ZOOTECNIA, 34., 1997, Juiz de Fora. Anais... Juiz de Fora: Sociedade Brasileira de Zootecnia, 1997. p.340.

MOULD, F.L.; ORSKOV, E.R.; MANNS, O. Associative effects of mixed feeds. I. Effects of type and level of supplementation and the influence of the rumen ph on cellulosis in vivo and dry matter digestion of various roughages. Animal Feed Science and Technology, v.10, n.1, p.15-30, 1983.

MÜLLER, L. Normas para avaliação de carcaças e concurso de carcaças de novilhos. Santa Maria: Universidade Federal de Santa Maria, 1980. 31p.

MÜLLER, L.; PRIMO, A.T. Influência do regime alimentar no crescimento e terminação de bovinos e na qualidade da carcaça. Pesquisa Agropecuária Brasileira, v.21, n.4, p.445-452, 1986.

MUNIZ, E.B. et al. Características das carcaças de novilhos F1 simental $x$ nelore alimentados com vários níveis de concentrado. In: REUNIÃO ANUAL DA SOCIEDADE BRASILEIRA DE ZOOTECNIA, 34., 1997, Juiz de Fora. Anais... Juiz de Fora: Sociedade Brasileira de Zootecnia, 1997. p.328.

NATIONAL RESEARCH COUNCIL - NRC. Nutrient requirements of beef cattle. 6.ed. Washington, DC: Academic Press, 1984. 90p.

OLIVEIRA, S.R.; COELHO DA SILVA, J.F.; VALADARES FILHO, S.C. et al. Rendimentos de carcaça e cortes básicos de novilhos Nelore recebendo rações com diferentes níveis de concentrado. In: REUNIÃO ANUAL DA SOCIEDADE BRASILEIRA DE ZOOTECNIA, 35., 1988, Botucatu. Anais... Botucatu: Sociedade Brasileira deZootecnia, 1998.p.164.

SATTER, L.D., SLYTER, L.L. Effect of ammonia concentration on rumen microbial protein production in vitro. British Journal of Nutrition, v.32, p.199, 1974.

SCHETTINI, M.A., PRIGGE, E.C., NESTOR, E.L. Influence of mass and volume of ruminal contents on voluntary intake and digesta passage of a forage diet in steers. Journal of Animal Science, v.77, p.1896-1904, 1999.

Van SOEST, P.J. Nutritional ecology of the ruminant. 2.ed. Ithaca: Cornell University Press, 1994. 476p.

VALADARES FILHO, S.C., COELHO DA SILVA, J.F., LEÃO, M.I. et al. Degradabilidade in situ da matéria seca e proteína bruta de vários alimentos em vacas em lactação. Revista Brasileira de Zootecnia, v.19, n.6, p.512:521, 1990.

VIEIRA, P.F. Efeito do formaldeído na proteção de proteína e lipídeos em rações. Viçosa, MG: Universidade Federal de Viçosa. 1980. 98p. Tese (Doutorado em Zootecnia) - Universidade Federal de Viçosa, 1980.

VIEIRA, R.A.M.; PEREIRA, J.C.; MALAFAIA, P.A.M. et al. The influence of elephant-grass (Pennisetum purpureum Schum. Mineiro variety) growth on the nutrient kinetics in the rumen. Animal Feed Science and Technology, v.67, p.151-161, 1997.

WALDO, D.R. Effect of forage quality on intake and forageconcentrate interactions Journal of Dairy Science, v.69, n.2, p.617-631, 1986.

WILLIANS, C.H.; DAVID, D.J.; IISMAA, O. The determination of chromic oxide in feces samples by atomic absorption spectrophotometry. Journal of Agricultural Science, v. 59, p.381-385, 1962.

ZERVOUDAKIS, J.T. Desempenho, características de carcaça e exigências líquidas de proteína e energia de bovinos suplementados no período das águas. Viçosa, $\mathrm{MG}$ : Universidade Federal de Viçosa, 2000. 84p. Dissertação (Mestrado em Zootecnia) - Universidade Federal de Viçosa, 2000.

Recebido em: 27/09/00 Aceito em: 14/09/01 